\title{
Correction: Evaluation of a social protection policy on tuberculosis treatment outcomes: A prospective cohort study
}

\section{Karen Klein, Maria Paula Bernachea, Sarah Iribarren, Luz Gibbons, Cristina Chirico, Fernando Rubinstein}

The third author's name is spelled incorrectly. The correct author name is Sarah Iribarren. The affiliation should read: Biobehavioral Nursing and Health Informatics, University of Washington, Seattle, Washington, United States of America.

The citation should read: Klein K, Bernachea MP, Iribarren S, Gibbons L, Chirico C, Rubinstein F (2019) Evaluation of a social protection policy on tuberculosis treatment outcomes: A prospective cohort study. PLoS Med 16(4): e1002788. https://doi.org/10.1371/journal.pmed. 1002788

\section{Reference}

1. Klein K, Bernachea MP, Irribarren S, Gibbons L, Chirico C, Rubinstein F (2019) Evaluation of a social protection policy on tuberculosis treatment outcomes: A prospective cohort study. PLoS Med 16(4): e1002788. https://doi.org/10.1371/journal.pmed.1002788 PMID: 31039158

G OPENACCESS

Citation: Klein K, Bernachea MP, Iribarren S, Gibbons L, Chirico C, Rubinstein F (2019) Correction: Evaluation of a social protection policy on tuberculosis treatment outcomes: A prospective cohort study. PLoS Med 16(5): e1002826. https:// doi.org/10.1371/journal.pmed.1002826

Published: May 31, 2019

Copyright: ๑ 2019 Klein et al. This is an open access article distributed under the terms of the Creative Commons Attribution License, which permits unrestricted use, distribution, and reproduction in any medium, provided the original author and source are credited. 